\title{
How Schools Can Best Support Somali Students and Their Families
}

\author{
Julie Mae Koch \\ University of Minnesota - Twin Cities
}

U. S. A.

Immigrant students often pose a challenge to educators. In particular, the Somali population of students presents a unique challenge due to the nature of their immigration, their history and culture, the fact that most are Muslim, and the fact that they are often labeled as "Black" by native-born peers. This article discusses the needs of Somali students and their families in education systems around the world and presents recommendations for schools to ease their transition. Future directions for research are also presented.

\author{
Introduction \\ History and Culture \\ Somalis in the Schools \\ Implications \\ Future Directions \\ References
}

\section{Introduction}

Aqoon la'aani waa iftiin la'aan (Being without knowledge is to be without light.) - Somali proverb -

Researchers in education have been working for years to understand questions related to the educational experiences of immigrants. Researchers have sought to answer many important questions: What factors act to promote or detract from the educational well-being of immigrant students? What are the experiences of immigrants in U.S. schools? Finally, how can those in education assist immigrants in their transition to life in a new country? (e.g., Bemak \& Chung, 2003; Kopala \& Esquivel, 1994; Olneck, 2004; Suárez-Orozco \& SuárezOrozco, 2001; Williams \& Butler, 2003).

This article explores these questions in regard to one unique group of immigrants, the Somalis, who have largely immigrated since 1990 due to civil unrest in their country. In the United States and Canada, Somalis comprise one of the largest groups of African-born Black Muslim immigrants (Young, Spitzer, \& Pang, 1999) with an estimated number of 70,000 Somalis in Canada. In 1990, the number of Somalis who entered the United States as refugees was 25 (Immigration and Refugee Services of America [IRSA], 2003). By 2001, the number of Somali refugees who entered the United States was 4,939. After September 11, 2001, this number dropped drastically but increased to 1,983 in 
2003. Somali refugees comprised the highest number of refugees from Africa entering the United States during the time period of 1990-2003 (IRSA, 2003). Numbers vary, but 35,000 Somalis are estimated to live in the state of Minnesota alone; some estimate the number to be about twice this due to secondary migration (African American Relief \& Development Initiative [ARADI], 2003; Darboe, 2003). In the United States, Minneapolis, Minnesota and Columbus, Ohio hold the largest concentrations of Somali immigrants (United States Department of State, 2003).

Due to the newness of this group in the United States and elsewhere, little research has been conducted regarding how to assist Somalis in their transition to their new lives (Kapteijns \& Arman, 2004). The research, however, indicates that the education of young people is one concern held by Somalis, regardless of their national residence, gender, and age (Birman, Trickett, \& Bacchus, 2001; Nderu, 2005a, 2005b; Robillos, 2001). The literature shows that Somali adolescents, in particular, may need extra support in their educational settings (Alitolppa-Niitamo, 2002; Forman, 2001; Hersi, 2005). It is also suggested that educational institutions should involve not only these students, but also their parents and families in the educational process (e.g., Nderu, 2005a, 2005b; Robillos, 2001). An additional question that this article seeks to answer, therefore, is how schools can best support Somali students and their families in educational settings.

\section{History and Culture}

Somalia is located in Eastern Africa. In 1960 British Somaliland and Somalia Italia acquired independence from colonialism and merged into one nation. In 1969 democracy in Somalia ended, and in 1991 full civil war ensued (Magnuson, 2002). It is estimated that in the early 1990's 1.5 million people died of starvation, over two million people were internally displaced, and 800,000 Somalis became international refugees (Magnuson, 2002). Warring in Somalia has continued, and although some regions have formed into nations, the governments of these nations remain unrecognized (Magnuson, 2002).

Somalia's population is mainly rural (Putman \& Noor, 1993). Its social structure consists of clans and subclans. Society is generally democratic and egalitarian, and decisions are typically made by men, although women's roles are also valued as extremely important. Most Somalis are Sunni Muslims, but women are typically allowed more freedom to pursue an education, work, and travel than in other Muslim cultures. While some children attended Koranic schools in Somalia, education services were disrupted due to civil war. Education in refugee camps was available but usually for a fee (Putman \& Noor, 1993). 


\section{Somalis in the Schools}

\section{Concerns Related to Immigration}

Somali students have a number of educational concerns directly related to the experience of immigration or being refugees. For example, in 2002, out of a reported 6,400 Somali immigrants in Finland, one-third of all families were headed by single mothers, and 600 were unaccompanied minors (AlitolppaNiitamo, 2002). Alitolppa-Niitamo (2002) found that among Somali high school students the most vulnerable groups were unaccompanied minors, who did not receive parental support or guidance, and the group labeled as "the generation in-between," in reference to the fact that students who arrive as adolescents are "between" the first (adult) and the 1.5 (arriving prior to age 12) generations. They arrive officially as "children" who require schooling but only have a few years to "learn" schooling, catch up to the curriculum, and graduate (Alitolppa-Niitamo, 2002, p. 282). These students were expected to explore their cultural/ethnic identity; deal with dislocation, loss, and trauma; learn a new cultural system; learn a new language; and become academically successful within a few years despite the fact that many did not have parents or family members to support them and typically had little educational background. They in turn experienced a massive cognitive burden, were tired and exhausted, had difficulty concentrating exhibited behavior problems, and lapsed into laissez-faire attitudes. Birman et al. (2001) provide an example of the insufficient time allowed for adolescents to complete their schooling:

One male student's sister did not get to graduate high school because of the age limit placed on being in school (21 years of age). She was placed in $9^{\text {th }}$ grade at age 18 and had to leave school in $12^{\text {th }}$ grade when she turned 22. This really upset her and her family. Her brother said, "Now she has to work everyday instead of having an education." (p. 8)

In one report related to the experience of Somali immigrants (Mattessich, 2000), Somalis listed causes of immigration-related stress such as separation from family and friends, language difficulties, and homesickness/isolation. Compared to three other immigrant groups, Somalis were more likely to have lived elsewhere before coming to their current location; more likely to be geographically separated from a spouse; more likely to be taking English classes if not confident with their fluency; more likely to be hopeful of returning to their native country; less likely to have visited their child's school; and less likely to have visited a park or a museum in the area.

Farid and McMahan (2004) echo these findings in their book, Accommodating and Educating Somali Students in Minnesota Schools. They state that immigration-related stress on Somali families includes concerns such as isolation, parenting, role reversals within families, financial pressures related to relatives still in Somali, and pressure related to having to care for relatives who may arrive in the United States. They also emphasize the effects of trauma and refugee life on Somali children and provide illustrations of how Somali children 
act out and how their parents and teachers are equipped (or not) to handle these situations. These concerns provide compelling reasons for the need for more support of Somali children in educational settings.

\section{Parental Concerns and Involvement}

Research related to the experience of Somali children has been conducted in school systems in the United States, Canada, and Finland. Parental involvement and support regarding education is considered important to the Somali students themselves. In one study from Finland, Somali students reported higher levels of parental support from both mothers and fathers than is found in students from other immigrant groups (Liebkind \& Jasinskaja-Lahti, 2000). Somali students also reported higher adherence to traditional family-related values, including support of parental authority and limitation of children's rights. While the researchers interpreted this as showing that Somalis are less acculturated than other students, it may in fact provide evidence for the crucial role that the family plays in the life of a Somali child.

However, it is not always possible for Somali parents to be as involved in a child's life as is desirable. As mentioned earlier, many Somali students live with extended family or guardians due to being separated from their parents or due to their parents' deaths. For students who do live with their families, there are still struggles regarding parental involvement. Alitolppa-Niitamo (2004) found that one challenge unique to Somali students was having parents who were illiterate, low-educated, and/or unemployed who, as a consequence, were isolated from society. Alitolppa-Niitamo (2002) examined the experiences of Somali youth in their transition to Finland. Findings indicated that Somali parents worried about their children adopting "Western" values and often needed to negotiate with schools regarding instruction of art, music, and physical education. Additionally, acculturation stress was found to limit the success of parents in supporting their children.

Nderu (2005a) conducted a qualitative study investigating Somali parental involvement in U.S. schools. Findings indicated that parents supported their children's education, faced some barriers to involvement in their children's schools, and praised U.S. schools in general. Overall, parents felt that involvement in education was a role the mother should fulfill. Parents felt that they supported their children's education by being teachers in the home and by providing them with nurturing at home. Parents said that they tried to help their children with homework, but some had difficulty understanding the assignments. Some parents said that they stayed away from their children's schools "to avoid interfering with the work of professionals" (Nderu, 2005b, p. 7). Conversely, teachers have been found to express frustration at the lack of involvement by parents and difficulty in communicating with parents (Birman et al., 2001). These findings were similar to those in other research, which found that schools could do more to involve immigrant parents and that there were communication difficulties between schools and parents. 
Nderu (2005b) outlined barriers to involvement in children's schooling, including covert norms of which parents are not informed in regard to appropriate behavior and expectations. Schools send mixed messages to these parents, as one parent explained:

Parents are always being told, "Please, please, come in to the school." But then as soon as you come in the school, the next thing is, "Well, wait a minute. You have to write your name down, give you a badge... and then we have to get security to escort you" (p. 8).

Parents noted they were accustomed to informal social relationships between teachers and parents outside of school and said that in the United States, their children's teachers rarely acknowledged them if they met outside of school. "Because being ignored violated their cultural expectations, they became uncomfortable about going into the teacher's territory to discuss their child's academic progress" (p. 8). Differences in the concept of time were also a barrier to parental involvement, because while U.S. teachers prefer to make appointments well in advance, Somalis may forget these appointments because of the strong oral tradition and lack of adherence to written calendars. The influx of written communication from schools also acted as a barrier. "[My] difficulty was understanding what was important among all the literature [I] received from the school. There is lots of paper to return and [l am] not sure which to return and which to ignore" (p. 8). Parents felt that teachers contacted them only when there was a problem with their children, usually at the point of "academic crisis."

Parents said they would like to receive formal orientation or instruction in regards to expectations by schools and that they would welcome home visits by teachers or school personnel. Nderu also suggested that the Somali community could do a better job of assisting new parents by teaching them about U.S. school expectations and recommended that schools offer a comfortable space where informal conversations and social interaction can occur.

Parents also talked about things they liked about U.S. schools, such as the fact that the education is free, that safety and security are provided to children both at the school and through transportation on school buses, and that at school children are free to play and learn.

\section{Social Interactions with Peers}

For Somali students, interactions with peers are often riddled with misunderstandings and with racial and religious discrimination. Forman (2001) conducted a qualitative study in both a U.S. and a Canadian high school in order to examine differences between the experiences of Somali students in each location and to see how Somali youths encounter "new social systems and struggle to comprehend their conditions and experiences" (p. 34). Forman asserts that schools as institutions play a large role in the formation of cultural identities of high school students and describes challenges to student adjustment. These include the pressure faced by single mothers, male responsibilities delegated to teenaged sons, and the circuitous manner in which 
Somalis eventually ended up in North America. Forman states that Somalis have "entered a social terrain that constitutes a complex emotional and political minefield" (p. 36), and that they do this unaware of racial dynamics in either the United States or Canada.

Forman (2001) includes findings related to White parents' opposition to immigrants in their children's schools. This supports other literature (Ajrouch \& Kusow, 2007; Kusow, 2006; Ighodaro, 1998; Mohamed, 2001) that found that Somalis in Canada, as Blacks and Muslims, faced discrimination, segregation, prejudice, and racism. Somali students faced a redefinition as Black youth. "For some, this is a disorienting revelation that demands considerable introspection and self-evaluation. They do not always fully comprehend the racial basis of their new social status" (Forman, p. 50). Somali students then "begin to conjoin their complaints with those of their black (sic) peers, voicing their resistance to real or perceived inequities in terms that conform strongly to those of North American black (sic) teens" (p. 50) and gradually, consciously and unconsciously, incorporate North American Black culture into their own cultural identity. This includes listening to hip-hop music, an alternative mix of Somali and Westernstyle clothing for Somali girls, hip-hop clothing for boys, and spoken "black [sic] English" (p. 55). The racial dynamics faced by Somalis, including White and nonWhite parental and peer attitudes and the perception of Somalis as Black, appear to be a salient issue that has been unaddressed.

Another major concern of Somali teens who participated in a different study was the cultural divide between themselves and their native-born peers, particularly in regards to dress and social activities such as being permitted to attend school dances (Robillos, 2001). Male adolescents especially expressed the desire for a place to socialize, play sports, or have fun after school. In another part of the report that listed available services, it is noted that while some adult tutoring and early childhood services were listed as available, not one service was listed as available to support adolescents or high school students. This illustrates a serious gap that may be filled in educational settings.

Regarding social concerns, Somali students often face alienation within the school setting. Students try to learn socially acceptable behavior in schools and balance their own culture with fitting in to the new school culture. Birman et al. (2001) conducted a study in order to make recommendations for improving Somali school and life experiences. Findings related to the students' experiences included themes of being different, fights with other students, religious issues, academic adjustment, history of trauma, family life, and future life in the United States. Students said that in order to avoid getting into trouble with their families or causing fights, they preferred to go out with other Somalis or with their families rather than native-born peers. Students said that they were unprepared for the amount of teasing and harassment they encountered when they entered the U.S. school, and were frustrated at not having opportunities to share their stories or experiences with other students or teachers. Students, both boys and girls, said that they got into conflicts with other students at the school because of teasing. In one example, female students tried to wear bandannas as head coverings in 
order to fit in, but school staff did not allow these because bandannas were seen as gang symbols. Somali students expressed negative impressions of their African-American native-born peers who appeared to show a lack of respect for teachers and who implied that Somalis were "acting White" by studying or trying to be "smart" (p. 6).

\section{Systemic Challenges Related to Education}

In addition to psycho-social concerns, the school system itself appears to pose unique challenges to educational success for Somalis. Hersi (2005) interviewed three school personnel about the educational and social experiences of Somali high school students in an urban high school. Educational challenges reported included both the need for native language literacy and the need for English language literacy. One concern was that students were placed in ageappropriate classes rather than academically-appropriate classes. Another concern was that students needed native language instruction to support English language instruction, and students were discouraged and frustrated when they entered mainstream classes. One finding was related to education in the "age of national and state standards" (p. 133). Students felt pressure to produce passing scores on standardized tests and felt that this pressure had a negative effect on the school drop-out rate among Somalis.

There are several examples of this systemic rigidity that appears to hinder Somali student success. Alitolppa-Niitamo (2004) found that assimilative and homogenizing practices of the school in her study were strong and that the institution of the school itself was rigid, including teachers who often greeted the Somalis with resistance or hostility. Hersi (2005) provides an example of a student who received zeros on his assignments because he did not label them in the "specific way the teacher required" (p. 136). Another example is given of three Somali girls who got in trouble for trying to wash their feet in the women's restroom sink in order to prepare for prayer. Birman et al. (2001) found that while students said that religion is a central part of their lives, their school had rigid restrictions that did not allow them to adhere to religious customs. An example was given of females who were forced to remove their head coverings for student ID photos.

Alitolppa-Niitamo (2004) used ethnographic data to develop a multivariate framework that shows how multiple factors interact in a complex way to affect academic performance of Somali students. The variables that interplay in this framework are incoming resources-including human capital, financial capital, and social capital-and receiving society variables (Alitolppa-Niitamo, 2004), all of which interact with the individual human agency to produce school achievement. Challenges unique to Somali students were found to be the absence or disruption of previous schooling; being unaccompanied minors; and having illiterate/low-educated/unemployed parents who, as a consequence, are isolated from society (Alitolppa-Niitamo, 2004). This article pointed out that Somali students may need individually tailored educational environments and that careful attention should be paid to the consequences of repeated migrations. 
"Understanding each student against his/her unique incoming resources and in her/his specific context of available social capital, instead of regarding students as representatives of a certain group, is almost certainly the key" (p. 99).

Another study was conducted through focus groups in a Somali community in the United States in order to determine how well available services matched the community's needs (Robillos, 2001). Education was found to be a major concern for both adults and children, specifically in the area of English proficiency. The groups recognized that there were some aspects of American schooling that would not change, such as mixed-gender activities at school, but also offered concrete recommendations for improvement of education. This included an increase in the number of tutors and counselors in schools, academic counseling for students, more English as a Second Language and Adult Basic Education classes, cultural diversity classes so non-Somali and Somali parents and school staff could learn about each other's cultures, and labeling foods so that children know what contains pork. They also recommended some flexibility regarding placing students according to age rather than academic ability, providing instructional materials such as computers at home, accommodating prayer time for Somali students, and creating activities that promote the understanding of Somali culture among native-born peers.

African American Relief \& Development Initiatives conducted a study in 2003 to identify opportunities and challenges in the Minnesota education system. Responses to "What are the primary challenges you see as seriously affecting education of Somali children and their parents?" included difference in Somali and U.S. educational systems, parents moving frequently, inadequate housing (causing parents to be unprepared for school issues), lack of support for parents provided by schools, social problems among youth caused by American culture, limited English language, teachers not being able to gain the trust of Somali children, discrimination and misunderstanding of Somali culture, and fear of Islam. Suggestions included the education of school staff about Somali culture, Somali liaisons at schools, more social workers and counselors in schools, more English assistance, education support services, Somali teachers, Somali counselors, and better pay for Somali teachers.

These findings echo those of Birman et al. (2001) who solicited recommendations from school teachers regarding how to improve understanding of Somali students. Recommendations by teachers included a "buddy system" or mentor system, teachers and school staff learning some words in Somali to show their interest in the culture, field trips through which Somali students would be exposed to hands-on language instruction, more instructional aides, a consistent disciplinary system, and a variety of specialized clubs or programs for Somali students. It was also suggested that students receive individualized planning due to considerable between-student variability. One interesting finding was that teachers found Somalis to be well-behaved in comparison to students from other African countries. Yet, they also found that Somali students did not integrate well into the larger school society. 
Birman et al. (2001) also noted a mismatch between students' and teachers' perceptions of experiences of trauma. While education professionals were frequently concerned about history of trauma and trauma re-emerging in the classroom, the students did not see themselves as traumatized. Teachers stated that they did not understand specific cultural issues or personal histories of the students but were fearful of asking students about their histories. Teachers expressed concerns about mental health and social adjustment issues and felt that they did not have enough training to deal with students who had past histories of trauma. Teachers stated that students needed "someone objective, yet caring, to talk to" and expressed the need for more counselors (Birman et al., p. 19). Teachers also felt that they could benefit from having mental health experts or counselors with whom they could consult or who could provide outreach to parents and training to school staff. These findings in general provide support for the notion that more assistance and provision of services is needed for Somali high school students.

While not based on research, one work that is important to note is that of Farid and McMahan (2004). Accommodating and Educating Somali Students in Minnesota Schools provides a useful, yet brief, handbook for educators to better understand issues faced by Somali students in schools. The authors provide an introduction to Somali culture and Islam; present an overview of the history of Somalia; and give examples of stress encountered by Somali families, the experiences of Somali students in public schools, and the effect of being a refugee on Somali students (Farid \& McMahan, 2004). Case studies are provided in order for the reader to get a better feel for the real issues Somali students and their families face in schools. These include a lack of familiarity with urban settings; the American custom of shaking of hands, which may be awkward for some Somali women; the lack of labels on foods in the school cafeteria; lack of places to pray; lack of understanding of Islam by school staff; the use of music and art in instruction; the difficulties that holidays such as Valentine's Day and Halloween bring; and bullying by native-born peers (Farid \& McMahan, 2004).

\section{Implications}

Across the literature, several themes emerge that provide support for the need to address the educational concerns of Somali adolescents and their families. Somali students and their families face a number of concerns, such as grief, loss, and trauma; family conflict; conflict with peers; racism and being identified as Black or African-American; differences from native-born peers regarding religion and dress; and typical adolescent concerns such as making friends and fitting in. Adolescents are particularly vulnerable because they are the generation "in-between." Not yet adults, no longer children, they struggle to define their cultural identities and achieve academic success within a time-limited period. Rather than assisting in the transition process, the apparent rigidity of the school system seems to be detrimental to the academic achievement and social integration of Somali students. While some needs of Somalis can be met through 
community or other agencies, educational settings seem to be a natural place for many needs to be addressed, due to the fact that students spend many days out of the year in school, that many of their concerns revolve around schooling, and that schools act as a "contact point" where immigrant parents who are otherwise isolated from non-Somalis can interact with Americans. Personnel within the schools have many ways to assist with Somali students' and families' transitions.

First, schools can provide individual and group guidance for academic, career, personal, and social issues that emerge for students. School staff must be aware of the past histories of their students, including the potential effects on development of separation from family and friends, isolation, and trauma (Davies \& Webb, 2000; Mattessich, 2000) and tailor their work with this population appropriately. Schools should remember that unaccompanied minors and the generation "in-between" are particularly vulnerable (Halcón et al., 2004; AlitolppaNiitamo, 2004; Birman et al., 2001) and may benefit from school-based group or individual counseling interventions. Schools must also consider that many Somalis, particularly women, have had exposure to torture (Jaranson et al., 2004; Halcón et al., 2004), which has important implications because single mothers head many Somali immigrant families and because the role of the mother is central to child-rearing in Somali culture (Dybdahl \& Hundeide, 1998). Schools should be prepared to work with Somali mothers who may desire assistance. Because of the importance placed on family (Dybdahl \& Hundeide, 1998), family counseling at the school may be a useful intervention. Schools should also be prepared to include family members when providing counseling for individual students. Building trust and rapport with the Somali students with whom they work will assist school staff in understanding their needs.

Second, schools might consider providing individualized planning for students, including academic and career planning to prepare for post-graduation. At least two studies found that parents desired more academic guidance for their students (ARADI, 2003; Robillos, 2001). Because English fluency was related to positive coping (Halcón et al., 2004), schools should carefully consider appropriate placement in English language courses. School staff are encouraged to advocate for the placement of students according to academic development rather than age (Birman et al., 2001; Hersi, 2005; Robillos, 2001). Schools should also promote more flexibility at the systemic, district, state, or national level regarding time allowed for incoming adolescent immigrants to complete high school (Hersi, 2005). School staff can collaborate with administrators to address the complexities of individual students' needs through a variety of services such as individual career counseling, education plans, or mentoring (Alitolppa-Niitamo, 2004, Birman et al., 2001).

Third, schools can proactively prevent many problems from occurring at the school, classroom, or large-group level. Birman et al. (2001) found that there was a "cultural divide" between Somalis and their native-born peers that made it difficult for Somali high school students to fit in. Others found that Somali adolescents experienced racism and discrimination (ARADI, 2003; Forman, 
2001; Liebkind \& Jasinskaja-Lahti, 2000). Here, staff may work within the school to lessen cultural misunderstandings between Somali adolescents and their native-born peers in order to promote a tolerant and welcoming environment (ARADI, 2003). Schools can provide education to native-born students about Somali culture (Robillos, 2001) and can provide education to Somali adolescents regarding socially acceptable behavior in the United States (Hersi, 2005). One recommendation was a "buddy" or mentor system for new students (Birman et al., 2001). Other recommendations might include education on topics related to issues that all students experience, such as stress management, study skills, and post-graduation and career planning.

Finally, schools can involve staff, administrators, district personnel, and members of the community as they work to educate children. At the community level, schools can work with Somali community leaders to provide a number of services for students and their families. Schools can work with cultural brokers in the Somali community in order to provide education to teachers, staff, and parents of native-born students regarding Somali culture and how to deal with trauma (Birman et al., 2001; Guerin et al., 2004; Nderu, 2005b; Robillos, 2001). Schools can collaborate with community organizations to provide culturally appropriate extracurricular activities for students (Birman et al., 2001). Somali community leaders can assist in providing education to Somali parents regarding expectations schools hold for parental involvement (ARADI, 2003; Hersi, 2005; Nderu, 2005b). Finally, schools can seek volunteer Somali liaisons or advocate for paid liaisons to assist both teachers and parents with communication (Birman et al., 2001).

Schools must keep in mind that to work with a Somali student is to work with his or her family. The role of parents, especially mothers, in educating their children is considered crucial in Somali culture (Dybdahl \& Hundeide, 1998). In addition, family support promotes positive coping among Somali children (Davies $\&$ Webb, 2000). However, while parents wanted to support their children's education (Alitolppa-Niitamo, 2002; Robillos, 2001), a major barrier was found to be English language proficiency (ARADI, 2003; Halcón et al., 2004; Nderu 2005b). Parents desire more English instruction (Robillos, 2001). Schools may collaborate with community agencies that provide English language classes or Adult Basic Education classes in order to provide this education at the school. English as a Second Language teachers or English teachers may be willing to volunteer to provide this service. Schools can advocate for the development of safe spaces for Somali parents, especially mothers, to come to school to socialize, learn about United States school culture, and get to know their children's teachers (Nderu, 2005b). Schools can also work toward such systemic changes as the labeling of foods (Farid \& McMahan, 2004; Robillos, 2001) and accommodation of prayer (Robillos, 2001). 


\section{Future Directions}

While many recommendations were made across the literature reviewed here, no studies indicated that a certain solution or intervention was actually effective with a Somali population. No studies looked at what schools are currently doing that may be working well. Few studies took into account Somali adolescents' experiences first-hand, and the voices of their native-born peers were markedly absent. No consideration was given to actual academic achievement as measured by such items as grade point average, college entrance examination scores, number of drop-outs, or number of Somali students who enroll in community or other colleges. No examination of students in rural versus urban settings or high poverty versus low poverty settings was found. The role of Islam in promoting resiliency, while mentioned, has not yet been explored.

The Somali immigrant population is relatively new to the United States. Therefore it makes sense that the literature in the areas of Somali education and mental health is in its infancy as well (Kapteijns \& Arman, 2004). It appears to be time to branch out from the existing research, much of which has focused on similar areas. Too many questions remain unanswered. How might Somalis benefit more from school-based individual or group services? How might changes in the school climate affect Somalis' attitudes toward college enrollment? What changes are possible through the mutual cultural education of administrators, staff, and immigrant parents? All of these questions can inform our understanding of how schools can best support Somali students and their families in educational settings.

\section{References}

African American Relief \& Development Initiative (ARADI). (2003). Opportunity and challenges in the state education system and its impact within the Somali community. Minneapolis, MN: Author.

Ajrouch, K. J., \& Kusow, A. M. (2007). Racial and religious contexts: Situational identities among Lebanese and Somali Muslim immigrants. Ethnic and Racial Studies, 30, 72-94.

Alitolppa-Niitamo, A. (2002). The generation in-between: Somali youth and schooling in metropolitan Helsinki. Intercultural Education, 13, 275-290.

Alitolppa-Niitamo, A. (2004). Somali youth in the context of schooling in metropolitan Helsinki: A framework for assessing variability in educational performance. Journal of Ethnic and Migration Studies, 30, 81-106.

Bemak, F., \& Chung, R. C. (2003). Multicultural counseling with immigrant students in schools. In P. B. Pedersen \& J. C. Carey (Eds.), Multicultural counseling in schools: A practical handbook (pp. 84-104). Boston: Pearson. 
Birman, D., Trickett, E. J., \& Bacchus, N. (2001). Somali refugee youth needs assessment: Executive summary. Baltimore: The Maryland Office for New Americans.

Darboe, K. (2003). New immigrants in Minnesota: The Somali immigration and assimilation. Journal of Developing Societies, 19, 458-472.

Davies, M., \& Webb, E. (2000). Promoting the psychological well-being of refugee children. Clinical Child Psychology and Psychiatry, 5, 541-554.

Dybdahl, R., \& Hundeide, K. (1998). Childhood in the Somali context: Mothers' and children's ideas about childhood and parenthood. Psychology and Developing Societies, 10, 131-144.

Farid, M., \& McMahan, D. (2004). Accommodating and educating Somali students in Minnesota schools. Saint Paul, MN: Hamline University Press.

Forman, M. (2001). "Straight outta Mogadishu": Prescribed identities and performative practices among Somali youth in North American high schools. TOPIA (Canadian Journal of Cultural Studies), 5, 33-60.

Guerin, B., Guerin, P., Diiriye, R., \& Yates, S. (2004). Somali conceptions and expectations concerning mental health: Some guidelines for mental health professionals. New Zealand Journal of Psychology, 33, 59-67.

Halcón, L. L., Robertson, C. L., Savik, K., Johnson, D. R., Spring, M. A., Butcher, J. N., et al. (2004). Trauma and coping in Somali and Oromo refugee youth. Journal of Adolescent Health, 35, 17-25.

Hersi, A. A. (2005). Educational challenges and sociocultural experiences of Somali students in an urban high school. In V. Gonzalez, E. H. Stefanakis, \& L. Minaya Rowe (Eds.), NABE (National Association of Bilingual Education) review of research \& practice (NRRP), Volume 3, (pp. 125-143). Mahwah, NJ: Lawrence Erlbaum.

Ighodaro, M. E. (1998). Experience of Somali students in Metro-Toronto school system-(Ontario). Unpublished doctoral dissertation, York University, Toronto, Canada [Abstract].

Immigration and Refugee Services of America (IRSA). (2003). Refugees admitted to the United States by nationality FY 1990-2003. Refugee Reports, 23.

Jaranson, J. M., Butcher, J., Halcón, L., Johnson, D. R., Robertson, C., Savik, K., S, et al. (2004). Somali and Oromo refugees: Correlates of torture and trauma history. American Journal of Public Health, 94, 591-598. 
Kapteijns, L., \& Arman, A. (2004). Educating immigrant youth in the United States: An exploration of the Somali case. Bildhaan: An International Journal of Somali Studies, 4, 18-43.

Kopala, M., \& Esquivel, G. (1994). Counseling approaches for immigrant children: Facilitating the acculturative process. School Counselor, 41, 352-359.

Kusow, A. M. (2006). Migration and racial formations among Somali immigrants in North America. Journal of Ethnic and Migration Studies, 32, 533-551.

Liebkind, K., \& Jasinskaja-Lahti, I. (2000). Acculturation and psychological wellbeing among immigrant adolescents in Finland: A comparative study of adolescents from different cultural backgrounds. Journal of Adolescent Research, 15, 446-469.

Magnuson, P. (Ed). (2002). Serving refugee students: Case studies of Somali, Bosnian, and Liberian students in Minnesota schools. Roseville, MN: Minnesota Department of Children, Families \& Learning.

Mattessich, P. (2000). Speaking for themselves: A survey of Hispanic, Hmong, Russian, and Somali immigrants in Minneapolis-Saint Paul. Saint Paul, MN: Wilder Research Center.

Mohamed, H. A. (2001). The socio-cultural adaptation of Somali refugees in Toronto: An exploration of their integration experiences (Ontario). Unpublished doctoral dissertation, University of Massachusetts at Amherst [Abstract].

Nderu, E. N. (2005a). Parental involvement in education: A qualitative study of Somali immigrants in the Twin Cities area. Unpublished doctoral dissertation, University of Minnesota-Twin Cities.

Nderu, E. N. (2005b). Somali families and parent involvement in schools. CURA (Center for Urban and Regional Affairs) Reporter, 35, 6-10. Retrieved May 1, 2006, from http://www.cura.umn.edu/reporter/05-Spr/Nderu.pdf

Olneck, M. R. (2004). Immigrants and education in the United States. In J. A. Banks \& C. M. Banks (Eds.), Handbook of research on multicultural education, (pp. 381-403). New York: Macmillan Publishing Company.

Putman, D. B., \& Noor, M. C. (1993). The Somalis: Their history and culture. CAL Refugee fact sheet series, No. 9. Washington, DC: Center for Applied Linguistics.

Robillos, M. U. (2001). Somali community needs assessment project. A report prepared for the Somali resource center. Minneapolis, MN: Center for Urban and Regional Affairs (CURA). 
Suárez-Orozco, C., \& Suárez-Orozco, M. (2001). Children of immigration. Cambridge, MA: Harvard University Press.

United States Department of State (2003). African refugee admission program. Washington, DC: Bureau of Refugees, Population, and Migration. Retrieved May 1, 2006, from http://www.usinfo.state.gov/topical/global/refugees/affs02119.htm

Williams, F. C. \& Butler, S. K. (2003). Concerns of newly arrived immigrant students: Implications. Professional School Counseling, 7, 9-14.

Young, E., Spitzer, D., \& Pang, F. (1999). Understanding the health care needs of Canadian immigrants. Edmonton: Prairie Center for Excellence on Immigration and Integration. Retrieved May 1, 2006, from http://pcerii.metropolis.net/frameset_e.html 